\title{
Mortality rates and cardiovascular disease burden in type 2 diabetes by occupation, results from all Swedish employees in 2002-2015
}

\author{
Sofia Carlsson ${ }^{1 *}\left(\mathbb{D}\right.$, Tomas Andersson $^{1,2}$, Mats Talbäck ${ }^{1}$ and Maria Feychting ${ }^{1}$
}

\begin{abstract}
Objective: To identify occupations where employees with type 2 diabetes have a high risk of cardiovascular disease (CVD) and mortality, and their prevalence of CVD risk factors. This study can contribute in the creation of targeted interventions at the workplace.

Research design and methods: This nationwide registry-based study included all employees with type 2 diabetes born in Sweden in 1937-1979 ( $n=180,620)$ and followed up in 2002-2015. We calculated age-standardized incidence (per 100,000 person-years) of all-cause and CVD mortality, ischemic heart disease (IHD) and stroke across the 30 most common occupations. Information on prognostic factors was retrieved from the National Diabetes Register.

Results: In males with type 2 diabetes, mortality rates were highest in manufacturing workers (1782) and machine operators (1329), and lowest in specialist managers (633). The risk of death at age $61-70$ years was $21.8 \%$ in manufacturing workers and $8.5 \%$ in managers. In females with type 2 diabetes, mortality rates were highest in manufacturing workers (1150) and cleaners (876), and lowest in writers and artists (458); the risk of death at age 61-70 years was $12.4 \%$ in manufacturing workers and $4.3 \%$ in writers and artists. The same occupations also had relatively high incidences of CVD mortality, IHD and stroke. Occupational groups with poor prognosis had high prevalence of CVD risk factors including poor glycemic control, smoking and obesity.
\end{abstract}

Conclusions: Manufacturing workers, machine operators and cleaners with type 2 diabetes have two to three times higher mortality rates than managers, writers and artists with type 2 diabetes. Major health gains would be made if targeted workplace interventions could reduce CVD risk factors in these occupations.

Keywords: Type 2 diabetes, Occupation, Workplace intervention, Mortality, Cardiovascular disease, Incidence, Epidemiology

\section{Introduction}

Type 2 diabetes is associated with serious complications, with cardiovascular disease (CVD) being the main cause of morbidity and mortality [1]. Because of its many comorbidities, diabetes is a major burden on the healthcare system [2]. In addition, type 2 diabetes has

*Correspondence: sofia.carlsson@ki.se

1 Institute of Environmental Medicine, Karolinska Institutet, 171 77 Stockholm, Sweden

Full list of author information is available at the end of the article adverse effects on work ability, as it is associated with increased sickness absence and early retirement $[3,4]$. Importantly, the risk of vascular complications can be reduced through a combination of lifestyle modifications and pharmacological interventions [5]. Major health and societal gains would be made if efficient secondary prevention could improve the prognosis for the large and growing number of people with type 2 diabetes $[6$, 7]. The workplace is a potentially important and underused arena for prevention; workplace interventions have shown promising results [8] and adults spend a large 
proportion of their time at work. The first step in such an approach is to identify occupations in which employees with type 2 diabetes have a high prevalence of CVD risk factors and are at high risk of adverse outcomes.

Several studies have shown that low socioeconomic status (SES) is associated with increased risk of CVD and mortality in individuals with type 2 diabetes $[9,10]$, but studies of specific occupations are lacking. Regarding the risk of developing type 2 diabetes, we recently reported a large variation across occupational groups; manufacturing workers, professional drivers and cleaners had 2-3 times higher rates of the disease than university teachers and physiotherapists [11]. The differences are far greater than those seen across socioeconomic groups [12]. We also found that occupations with high type 2 diabetes incidence were characterized by high prevalence of overweight, smoking and low physical fitness [11]. This could put employees with type 2 diabetes in these occupations at high risk of CVD. Furthermore, workplace factors such as irregular working hours, shift work, stress and physically strenuous work may hinder optimal self-management and contribute to poor glycemic control and excess risk of vascular complications in some occupations [1316]. At present, it is not clear if and how the prognosis of people with type 2 diabetes differs across occupational groups.

To address this knowledge gap, we investigated the risk of all-cause mortality and CVD mortality and morbidity in males and females with type 2 diabetes across the 30 most common occupational groups among all people gainfully employed in Sweden. The aim was to identify occupations where employees with type 2 diabetes have a high risk of CVD and mortality and to describe their prevalence of key CVD-risk factors.

\section{Research design and methods Registry linkage}

This nationwide study was based on the Prescribed Drug Register (PDR), the National Patient Register (NPR), the Cause of Death Register, the National Diabetes Register (NDR) and the Longitudinal integration database for health insurance and labour market studies (LISA by its Swedish acronym) (Additional file 1: Figure S1). The registers were linked using the personal identification numbers assigned to Swedish residents upon birth or immigration. The study was approved by the ethical review board in Stockholm (2017/706-31).

\section{Study population}

We used LISA [17] to identify all individuals born in Sweden 1937-1979 and selected those who were gainfully employed at any time between 2001 and 2013 $(\mathrm{n}=4,398,117 ; 2,245,231$ males and 2,152,886 females);
The birth years selected ensured that the participants were younger than 65 years in 2001 (the first year for which we had occupational information) and older than 35 years at the end of follow-up in 2015. This was our source population, in which we aimed to identify all people with type 2 diabetes.

\section{Diabetes}

Prevalent cases of diabetes in 2001-2013 were identified through the NPR, the NDR and the PDR. The NPR contains information on all diagnoses from hospital admissions nationwide since 1987 and from outpatient specialist care since 2001, coded based on the Swedish version of the International Classification of Disease (ICD-10 since 1997) [18]. In the NPR, ICD codes E11 (type 2 diabetes) and E14 (unspecified diabetes) were used as indicators of type 2 diabetes. The PDR records all filled prescriptions since July 2005, based on the Anatomical Therapeutic Chemical (ATC) classification system [19]. ATC group A10 (insulin and oral antidiabetic drugs) was used to identify diabetes. If a case was identified solely through the PDR, age at first prescription $\geq 35$ years was used as an indicator of type 2 diabetes. The NDR was created in 1996 with the aim of monitoring the health of people with diabetes [20]. The NDR records clinical characteristics for people over 18 years diagnosed with type 1, type 2 or gestational diabetes and covers $90 \%$ of all diabetes patients. In total, we identified 180,620 individuals with type 2 diabetes who were followed up for CVD and mortality. Data on the incidence and prevalence of type 2 diabetes by occupation in this population have been published previously [11].

\section{Occupation}

Information on occupation was obtained by linkage to the LISA database [17]. LISA holds annual data from 1990 onwards, encompassing all Swedish citizens $\geq 16$ years of age as of December 31 each year. Main occupation, i.e., the occupation with the highest taxable income, is recorded for each person in November each year. Occupations are classified based on the Swedish Standard Classification of Occupations 1996 (SSYK96) [21], which is a national version of the International Standard Classification of Occupations [22]. LISA also includes information on highest attained level of education.

\section{Risk factors}

We used the NDR to collect information on CVD risk factors in individuals with type 2 diabetes for the period 2001-2013. This included information on duration of diabetes, glycated hemoglobin $\mathrm{A} 1 \mathrm{c}\left(\mathrm{HbA}_{1 \mathrm{c}}\right)$, albuminuria, systolic blood pressure, low-density lipoprotein (LDL) cholesterol, estimated glomerular filtration rate 
(eGFR, using the Modification of Diet in Renal Disease equation), body mass index (BMI), smoking and physical activity. We used all information recorded while the person was gainfully employed. Information from NDR was available for $71 \%$ of males with type 2 diabetes and $67.2 \%$ of females with type 2 diabetes from the time when they were employed. No corresponding information was available for people without diabetes.

\section{Outcomes}

People with type 2 diabetes were followed for mortality and cardiovascular morbidity between 2002 and 2015 in the NPR and the Cause of Death Register. We used the outcomes all-cause mortality, CVD mortality (ICD-10 codes I00-I99), ischemic heart disease (ICD-10: I20-I25) and stroke (ICD10: I61-I64) (including fatal). Additionally, we followed the entire source population, consisting of all those who were gainfully employed in 2001-2013, for the same outcomes.

\section{Statistical analyses}

In the SSYK96 [21], there are 113 occupational groups at the three-digit level. We chose to focus on the 30 most common occupations in males and females, respectively, which were selected based on the total number of person-years of follow-up in each occupation. We calculated age-standardized mortality and CVD incidence from 2002 to 2015 and 95\% confidence intervals (CIs) across occupational groups in people with type 2 diabetes. Employees were followed from the first recording indicating T2D in any of the registers. Incidence is expressed per 100,000 person-years in this paper. The age distribution of the total employed population with type 2 diabetes from 2002 to 2015 was used for weighting. Since there were few observations in some occupations at certain ages, we standardized by use of a multivariable logistic model for each occupation, with age and calendar year as explanatory variables in the model; age was included as a third-degree polynomial function. We applied the estimated model to the total employed population with type 2 diabetes to predict annual incidence of the outcome event. All analyses were run separately in males and females. Standardized incidence ratios (SIRs) were also calculated for each occupation compared with the total employed population with type 2 diabetes. We estimated the 10-year risk of all-cause mortality, CVD mortality, IHD and stroke at age 60 years by occupation in people with type 2 diabetes conditioned on being alive at that age. The risk were calculated as the complement to the estimated probability of being event-free through ages 61 to 70 years in 2015 , using the age and occupation specific cumulative incidence from the same model for standardization. Based on the 10-year risk at age 60 years, we also estimated the attributable risk percentage (AR\%) for each occupation using the formula ( $R R-1) / R R$, where $R R$ is the relative risk in each occupation using the occupation with the lowest risk as reference. This number shows the proportion of cases that would be eliminated if the risk in a specific occupation was equal to that in the occupation with the lowest risk. The analyses were repeated in the source population consisting of the total employed population (Additional file 1: Tables S10-S13).

\section{CVD risk factors}

CVD risk factors in people with type 2 diabetes across occupational groups were presented as mean values and standard deviations for continuous variables. We also calculated the proportion within each occupational group that was above a target level for each risk factor. In line with current treatment guidelines [23, 24], we used the cut-off $>7.0 \%(53 \mathrm{mmol} / \mathrm{mol})$ for $\mathrm{HbA}_{1 \mathrm{c}},>140 \mathrm{mmHg}$ for systolic blood pressure, $>2.5 \mathrm{mmol} / \mathrm{l}$ for LDL cholesterol, and $B M I \geq 30 \mathrm{~kg} / \mathrm{m}^{2}$ for obesity. In addition, albuminuria was defined as either microalbuminuria (2/3 positive results, i.e., a urinary albumin/creatinine ratio of $3-30 \mathrm{mg} / \mathrm{mmol}$ or urinary albumin clearance of $20-200 \mu \mathrm{g} / \mathrm{min}$ within one year) or macroalbuminuria (a urinary albumin/creatinine ratio $>30 \mathrm{mg} / \mathrm{mmol}$ or urinary albumin clearance $>200 \mu \mathrm{g} / \mathrm{min}$ ), low physical activity as being active for at least $30 \mathrm{~min}$ less than once per week, and smoking as smoking at least one cigarette per day.

\section{Results}

\section{Characteristics}

There were 180,620 individuals with type 2 diabetes, among whom there were 14,881 deaths, including 4661 from CVD, during 1.5 million years of follow-up. In the general population, there were 167,575 deaths over 45.7 million years of follow-up. Incidence of all-cause mortality, CVD mortality, IHD and stroke was higher in individuals with type 2 diabetes than in the general population, in both males and females, and this difference was seen across all occupational groups (Figs. 1 and 2, Additional file 1: Figures S2-S5, Tables S2, S3). The risk of death at age $61-70$ years was $13.8 \%$ in males and $10.0 \%$ in females with type 2 diabetes, compared with $8.7 \%$ and $5.6 \%$, respectively, in the general population. Males had higher mortality, IHD and stroke incidence than females, and this difference was seen in those with type 2 diabetes as well as in the general population (Additional file 1: Table S1).

\section{Males with type 2 diabetes}

In males with type 2 diabetes, all-cause mortality rates (per 100,000 person-years) were highest in 


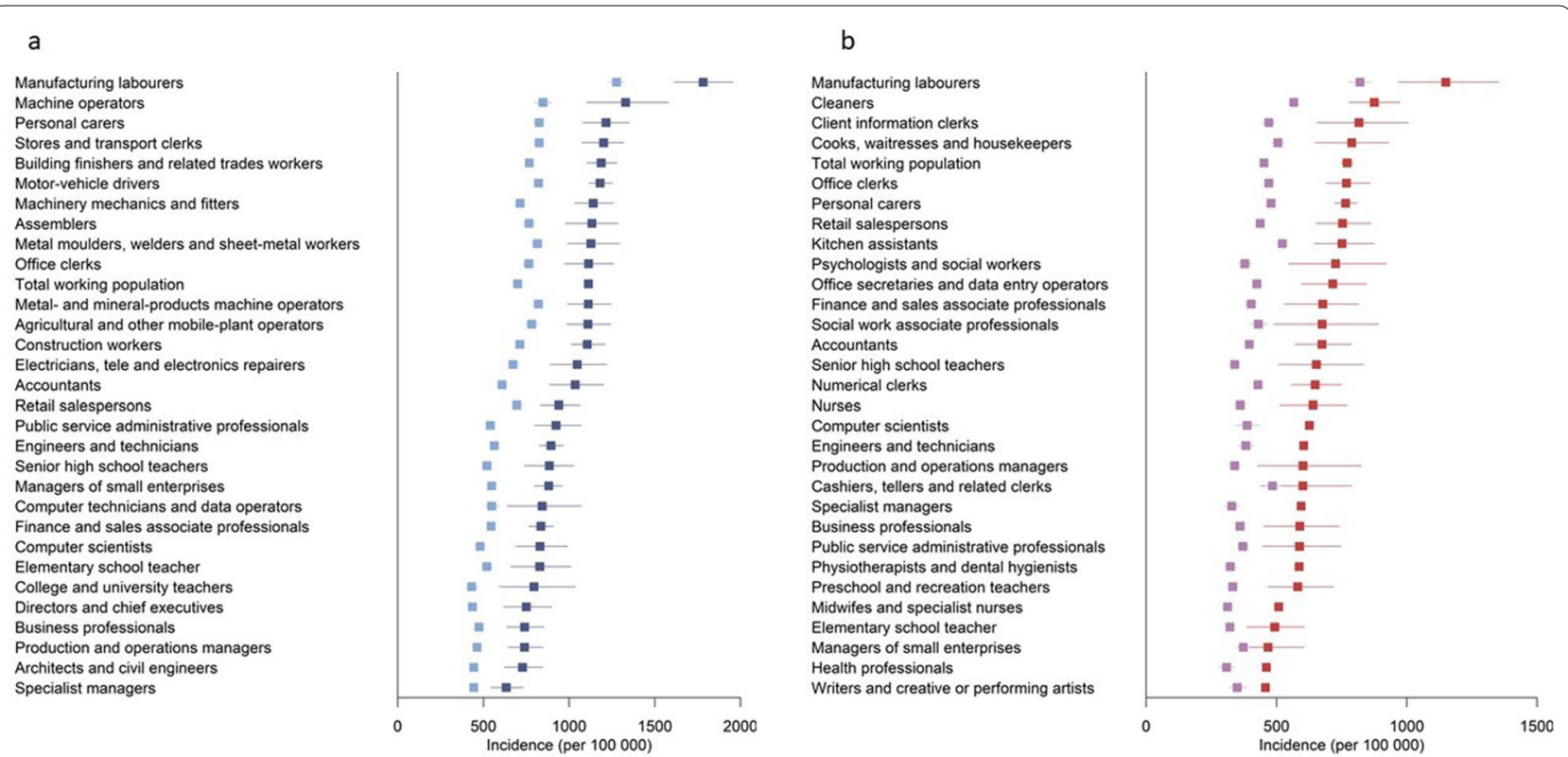

Fig. 1 a Age-standardized all-cause mortality (per 100,000 person-years) from 2002 to 2015 across the 30 most common occupations in Swedish males. Blue squares, males with type 2 diabetes; light blue squares, all males. b Age-standardized all-cause mortality (per 100,000 person-years) from 2002 to 2015 across the 30 most common occupations in Swedish females. Red squares, females with type 2 diabetes; light purple squares, all females

Manufacturing labourers Metal moulders, welders and sheet-metal workers Motor-vehicle drivers

Office clerks

Metal-and mineral-products machine operators

Assemblers

Building finishers and related trades workers

Stores and transport clerks

Machine operators

Machinery mechanics and fitters

Agricultural and other mobile-plant operators

Total working population

Construction workers

Retail salespersons

Managers of small enterprises

Accountants

Electricians, tele and electronics repairers

Finance and sales associate professionals

Engineers and technicians

Architects and civil engine

Business professionals

Public service administrative professionals

Elementary school teacher

Computer scientists

Senior high school teachers

Production and operations managers

Directors and chief executives

Specialist managers

College and university teachers

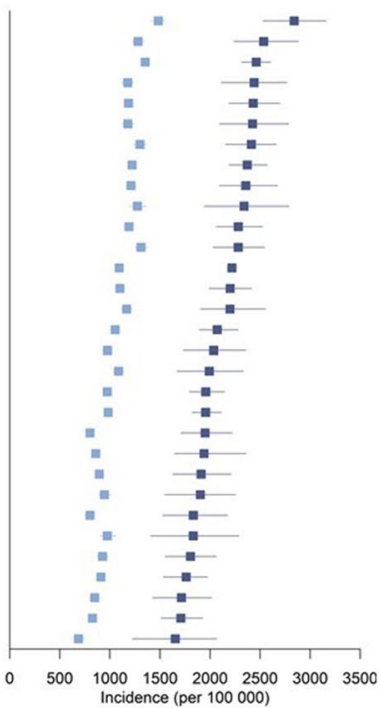

Social work associate professionals
Cashiers, tellers and related clerks
Manufacturing labourers
Health professionals
Psychologists and social workers
Retail salespersons
Managers of small enterprises
Personal carers
Kithen assistants
Office clerks
Cleaners
Total working population
Office secretaries and data entry operators
Cooks, waitresses and housekeepers
Writers and creative or performing artists
Preschool and recreation teachers
Client information clerks
Midwifes and specialist nurses
Nurses
Numerical clerks
Accountants
Public service administrative professionals
Senior high school teachers
Finance and sales associate professionals
Specialist managers
Elementary school teacher
Production and operations managers
Computer scientists
Business professionals
Physiotherapists and dental hygienists
Engineers and technicians

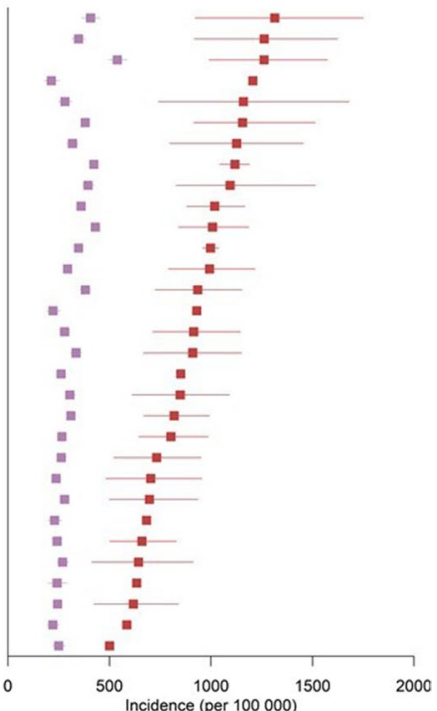

Fig. 2 a Age-standardized incidence of ischemic heart disease (per 100,000 person-years) from 2002 to 2015 across the 30 most common occupations in Swedish males. Blue squares, males with type 2 diabetes; light blue squares, all males. b Age-standardized incidence of ischemic heart disease (per 100,000 person-years) from 2002 to 2015 across the 30 most common occupations in Swedish females. Red squares, females with type 2 diabetes; light purple squares, all females 
manufacturing workers (1782), machine operators (1329) and personal carers (1215), and lowest in specialist managers (633) (Fig. 1, Additional file 1: Table S4). The same occupational groups also had the highest and lowest CVD mortality rates, respectively (Additional file 1: Figure S2). SIR calculations indicated that manufacturing workers had 1.59 (95\% CI 1.44-1.76) times higher mortality rates compared with the total employed population with type 2 diabetes and specialist managers had $43 \%$ (SIR 0.57, 95\% CI 0.49-0.66) lower mortality rates. The 10 -year risk of death at age 60 years was $21.8 \%$ in manufacturing workers and $19.9 \%$ in machine operators compared with $8.5 \%$ in specialist managers (Fig. 3, Additional file 1: Table S4). Estimation of AR\% indicated that $61 \%$ of all deaths at age 61-70 years among manufacturing workers with type 2 diabetes would be eliminated if they had the same mortality risk as specialist managers with type 2 diabetes (Additional file 1: Table S4).

The incidence of IHD was highest in manufacturing workers (2814) and metal molders, welders, and sheetmetal workers (2536), and lowest in college/university teachers (1653) (Fig. 2 and Additional file 1: Table S5). Stroke incidence was highest in motor vehicle drivers (771), followed by manufacturing workers (753), and lowest in computer technicians/data operators (447) (Additional file 1: Figure S3 and Table S5). The risk of IHD at age $61-70$ years was $24.7 \%$ in manufacturing workers compared with $16.9 \%$ in college/university teachers.
Motor vehicle drivers and manufacturing workers had a 9.6\% risk of a stroke event at age 61-70 years; the risk among computer technicians/data operators was $4.5 \%$.

\section{Females with type 2 diabetes}

In females with type 2 diabetes, mortality rates (per 100,000 person-years) were highest in manufacturing workers (1150) and cleaners (876), and lowest in health professionals (461) and writers/artists (458) (Fig. 1, Additional file 1: Table S6). SIR calculations indicated that manufacturing workers with type 2 diabetes had 1.53 times higher and writers/artists had $41 \%$ lower mortality rates than the general population with type 2 diabetes. Similar findings were seen for CVD mortality (Additional file 1: Figure S4, Table S6). The risk of death at age 61-70 years in females with type 2 diabetes was highest in manufacturing workers (12.4\%), office clerks (11.9\%), and kitchen assistants (11.6\%), and lowest in writers/ artists (4.3\%) (Fig. 3, Additional file 1: Table S6). Estimation of $\mathrm{AR} \%$ indicated that $65.5 \%$ of all deaths at age 61-70 years in manufacturing workers with type 2 diabetes would be eliminated if they had the same mortality risk as writers/artists with type 2 diabetes (Additional file 1: Table S6).

Incidence of IHD was highest in social work professionals (1314; this includes youth recreation leaders and treatment assistants), manufacturing workers (1262), and cashiers and tellers (1262), and lowest in engineers and

\section{a}

Manufacturing labourers
Machine operators
Metal-and mineral-products machine operators
Assemblers
Motor-vehicle drivers
Agricultural and other mobile-plant operators
Retail salespersons
Stores and transport clerks
Construction workers
Machinery mechanics and fitters
Metal moulders, welders and sheet-metal workers
Office clerks
Personal carers
Building finishers and related trades workers
Public service administrative professionals
Total working population
Accountants
Engineers and technicians
Electricians, tele and electronics repairers
Finance and sales associate professionals
Managers of small enterprises
Computer technicians and data operators
Elementary school teacher
Directors and chief executives
Senior high school teachers
Computer scientists
Architects and civil engineers
College and university teachers
Business professionals
Production and operations managers
Specialist managers

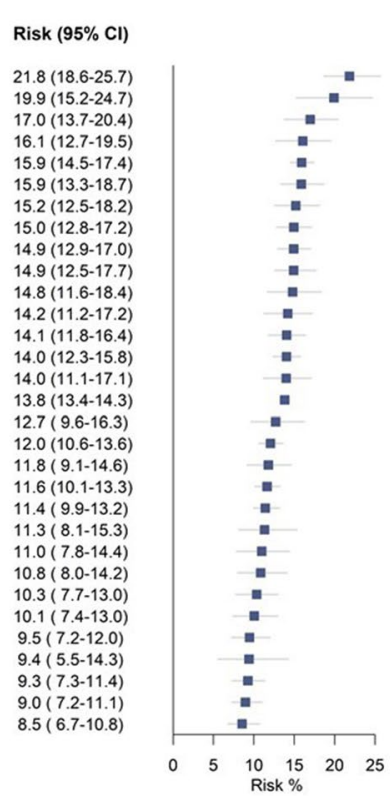

\section{b}

Manufacturing labourers

Office clerks

Kitchen assistants

Cooks, waitresses and housekeepers

Numerical clerks

Accountants

Computer scientists

Personal carers

Client information clerks

Cleaners

Total working population

Office secretaries and data entry operators

Retail salespersons

Public service administrative professionals

Business professionals

Nurses

Senior high school teachers

Managers of small enterprises

Social work associate profession

Midwifes and specialist nurses

Prance and sales associate professionals

Production and operations managers

Engineers and technicians

Engineers and technic
Specialist managers

Preschool and recreation teachers

Physiotherapists and dental hygienists

Psychologists and social workers

Elementary school teacher

Health professionals

Writers and creative or performing artists

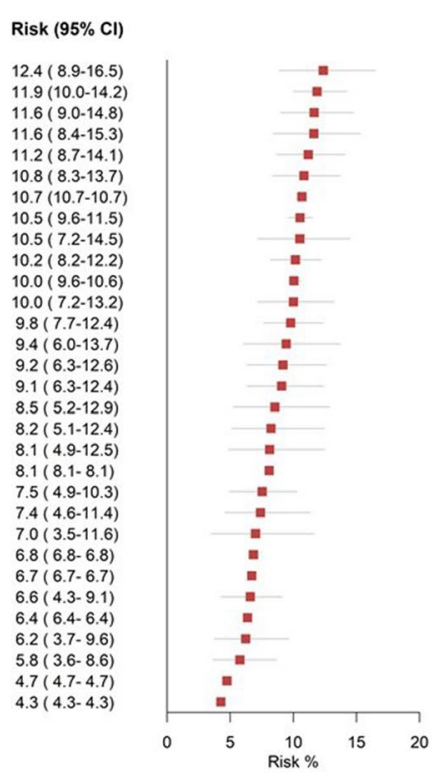

Fig. 3 a The risk (per 100 persons) of dying at age 61-70 years in males with type 2 diabetes across the 30 most common occupations in Swedish males. $\mathbf{b}$ The risk (per 100 persons) of dying at age 61-70 years in females with type 2 diabetes across the 30 most common occupations in Swedish females 
technicians (501) (Fig. 2, Additional file 1: Table S7). The risk of IHD at age $61-70$ years was $11.5 \%$ in manufacturing workers, $11.1 \%$ in social work professionals, and $7.8 \%$ in engineers and technicians. The incidence of stroke was highest in manufacturing workers (534)-six times higher than in health professionals (87) (Additional file 1: Figure S5 and Table S7) - with the risk of being affected at age $61-70$ years being $4.6 \%$ in manufacturing workers and $1.6 \%$ in health professionals.

In both males and females with type 2 diabetes, the incidence was highest in occupations characterized by low SES (Additional file 1: Tables S4-S7) according to the classification used by Statistics Sweden [25], including both skilled and unskilled manual laborers (occupations that require less than 12 years' education).

\section{CVD risk factors in males and females with type 2 diabetes}

Mean duration of type 2 diabetes was 6.3 years in females and 6.4 years in males and did not seem to vary by occupation (Additional file 1: Tables S8, S9). Occupations with high mortality and CVD rates were characterized by higher prevalence of CVD risk factors than occupations with low rates (Additional file 1: Tables S8, S9). As an example, male manufacturing workers had a higher prevalence of smoking ( 25.1 vs. $10.0 \%, p<0.0001)$, obesity ( 50.7 vs $42.5 \%, p<0.0001$ ), albuminuria ( 24.3 vs $19.6 \%, p$ 0.0030) and $\mathrm{HbA}_{1 \mathrm{c}}$ levels above $7 \%(53 \mathrm{mmol} /$ mol) (47.6 vs. $38.4 \%, p<0.0001)$ than male specialist managers. Similar results were seen when comparing female manufacturing workers to female writers/artists regarding smoking ( 25.6 vs. $12.7 \%, p<0.0001$ ), albuminuria (16.8 vs $8.9 \%, p$ 0.0109) and $\mathrm{HbA}_{1 \mathrm{c}}$ levels above $7.0 \%$ (53 mmol/l) (42.6 vs $31.3 \%, p$ 0.0030). Regarding LDL cholesterol, systolic blood pressure and low physical activity, the variation across high- to low-risk occupations was less consistent. As shown in Fig. 4, there was a clear positive association between all-cause mortality and the proportion with $\mathrm{HbA}_{1 \mathrm{c}}$ levels above target within the 30 most common occupations for males and females. Similar associations with $\mathrm{HbA}_{1 \mathrm{c}}$ were seen for incidence of CVD mortality, IHD and stroke (Additional file 1: Figures S6-S8).

\section{The total employed population}

Among the total male employed population, the highest all-cause and CVD mortality, stroke and IHD incidence was seen in manufacturing workers, followed by machine operators (mortality) and motor vehicle drivers (IHD and stroke) (Figs. 1 and 2, Additional file 1: Figures S2, S3, Tables S10, S11). All-cause mortality, CVD mortality, IHD and stroke incidence in the total female employed population was highest in manufacturing workers followed by cleaners (Figs. 1, 2, Additional file 1: Figures S4, S5 and Tables S12, S13).

\section{Discussion}

This nationwide descriptive study revealed large variation in all-cause mortality, CVD mortality, and the incidence of IHD and stroke among people with type 2 diabetes across the 30 most common occupational groups in Sweden. In females with type 2 diabetes, mortality rates ranged from 458-1150 per 100,000 person-years and were highest in manufacturing workers and cleaners and lowest in health professionals and writers/artists. In males with type 2 diabetes, mortality rates were highest in manufacturing workers and machine operators and lowest in architects, civil engineers, and specialist managers, ranging from 633 to 1782 per 100,000 person-years. The same occupations had high CVD mortality, IHD and stroke incidence. Occupations associated with poor type 2 diabetes prognosis were characterized by higher prevalence of CVD risk factors, including poor glycemic control, smoking, obesity, and low physical activity.

As far as we know, this is the first study to give a comprehensive overview of the prognosis of people with type 2 diabetes across occupational groups. However, a Chinese study found lower death rates in nurses with diabetes than the general population of patients [26], which is in line with our findings. Previous studies indicate that low SES is associated with higher rates of mortality and CVD in individuals with type 2 diabetes $[9,10]$. In support of this, we found that occupations where employees with type 2 diabetes had a poor prognosis were characterized by low SES. However, our analysis showed large variation between occupational groups within the low socioeconomic stratum, e.g., CVD mortality rates were $33 \%$ higher in male manufacturing workers with type 2 diabetes than in male machine operators and assemblers with type 2 diabetes, and 77\% higher in female manufacturing workers with type 2 diabetes than in female cleaners with type 2 diabetes.

Previous studies based on general working populations found the highest death rates among factory workers, cleaners, and construction workers [27-29]. We could confirm these findings in our population and extend them by showing that having type 2 diabetes increased the risk even further in these already vulnerable groups, e.g., manufacturing workers with type 2 diabetes had about twice the IHD rates and $40 \%$ higher mortality rates than the general population of manufacturing workers. Previous findings based on the Swedish National Diabetes Register indicate that smoking, physical inactivity and $\mathrm{HbA}_{1 \mathrm{c}}$ levels above target are the strongest predictors of mortality in type 2 diabetes [30]. In line with this, we observed that these risk factors were more prevalent in 


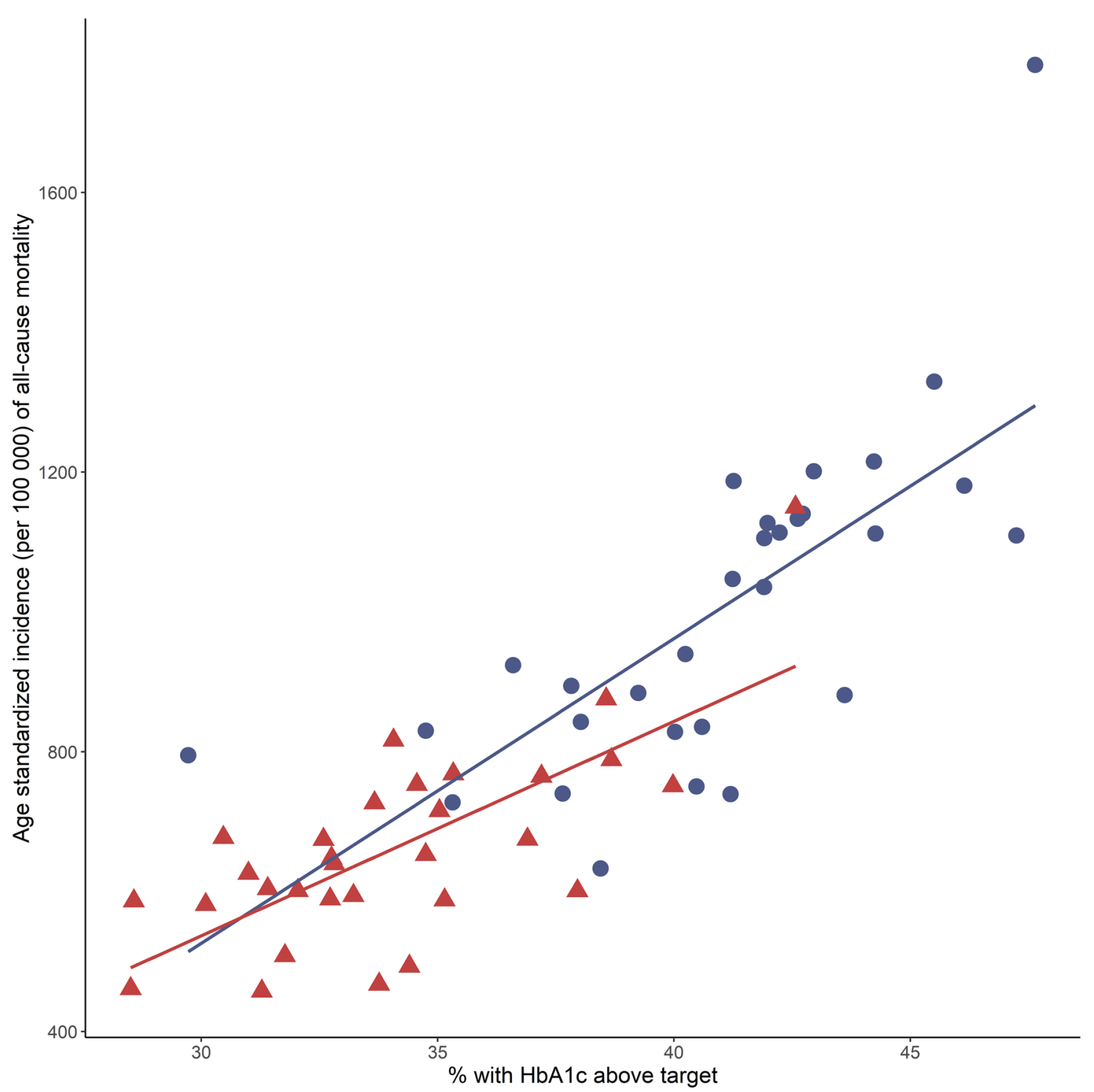

Fig. 4 Proportion (\%) with $\mathrm{HbA}_{1 \mathrm{c}}$ levels above target (>7.0\% (53 mmol/mol)) and age-standardized all-cause mortality (per 100,000 person-years) from 2002 to 2015 in people with type 2 diabetes, across the 30 most common occupations in Swedish males and females. Blue circles, males; red triangles, females

the occupations where people with type 2 diabetes had the poorest prognosis.

We have previously demonstrated that manufacturing workers, cleaners and machine operators have higher incidence of type 2 diabetes than other occupational groups and higher prevalence of overweight, smoking, and low physical fitness at young age (18-40 years) [11]. In the present study, we show that if such workers develop type 2 diabetes, they have a poorer prognosis than their counterparts in other occupational groups, including $2-3$ times higher mortality rates and high incidence rates of
IHD and stroke. Out of all occupational groups, manufacturing workers fared worst: they had the highest type 2 diabetes risk and the poorest prognosis. In absolute terms, the risk of death at age 61-69 years in manufacturing workers with type 2 diabetes was $21.8 \%$ (males) and $12.4 \%$ (females), compared with $8.5 \%$ in specialist managers (males) and $4.3 \%$ in writers/artists (females). Manufacturing workers were also most often smokers and most often had albuminuria and $\mathrm{HbA}_{1 \mathrm{c}}$ levels and systolic blood pressure above target. Targeted interventions seem warranted, and the preventive potential 
appears substantial; estimations of AR\% indicate that $>60 \%$ of all deaths at age $61-70$ years among manufacturing workers with type 2 diabetes would be eliminated if they had the same death risk as workers with diabetes in low-risk occupations. This is particularly important as type 2 diabetes is common, affecting $14.9 \%$ of male and $10.7 \%$ of female manufacturing workers 55 years or older in Sweden [11]. It should be noted that the job title serves as a risk indicator in this context, and we are not proposing that occupation per se is a causal factor in relation to diabetes complications.

Efficient first and secondary prevention that reduces the risk of type 2 diabetes and its complications would benefit public health and could lead to major healthcare and productivity gains. A US study from 2016 estimated that diabetes accounted for the largest healthcare costs out of all medical conditions [31]. Moreover, a recent Swedish study found that costs related to being absent from work exceeded those for hospital-based care [32]. Vascular complications are preventable [5] and there are studies showing that workplace interventions, including supervised group sessions promoting healthy eating, physical activity, and self-management in employees with type 2 diabetes, may improve diabetes outcomes, including $\mathrm{HbA}_{1 \mathrm{c}}$ levels [8]. In this context, it should be noted that adaptations of diabetes prevention programs to workplace settings have also shown promising results [33]. There is a close relationship between T2D and several CVDs including heart failure [34] and arterial fibrillation [35] and once both conditions are present, mortality is increased substantially. Ideally, all employees in occupations where the risks of type 2 diabetes and CVD are high should be targeted with interventions to increase physical activity, reduce weight gain, and promote smoking cessation. This could reduce the risk of both conditions. Further research in this area is warranted, both for confirmation of our findings and for addressing aspects that we did not cover, including the burden of sickness absence, disability pension and early retirement attributable to diabetes in different occupational groups, the risk of microvascular complications by occupation, and the extent to which working conditions affect the prognosis of individuals with type 2 diabetes.

The strengths of this study included the nationwide design that comprised the entire Swedish employed population and information collected from national registers, with virtually no loss to follow-up. Information on occupation came from a national database that is updated annually and has a 95\% completeness [17]. Diabetes cases were identified through a combination of patient, prescription, and diabetes registers. Since the PDR can be expected to cover all pharmacologically treated patients and the NDR covers $>90 \%$ of all patients [20], we have probably identified most cases. However, undiagnosed diabetes will be missed, and the proportion of such cases may differ between occupations. Type 2 diabetes diagnosis was based on ICD code or age $\geq 35$ years at the time of the first prescription of diabetes medication. This means that some individuals with adult-onset autoimmune diabetes will be included. As this is relatively rare, it is unlikely to affect the results significantly. In addition, the NDR provided us with detailed information on CVD risk factors, including $\mathrm{HbA}_{1 \mathrm{c}}$ levels, for most individuals with type 2 diabetes. Limitations include the lack of information on CVD risk factors in the general population, which would have been valuable for comparison of risk factor patterns. We also lacked information on working conditions, such as stress, working hours, shift work and physical demands, which may influence the risk of mortality and CVD and contribute to differences in risk factor patterns. There may also be differences in antidiabetic and cardioprotective treatment across occupational groups which could affect prognosis. The NPR and cause of death register were used for outcome assessment. The validity of these registers is high for most diagnoses, including myocardial infarction and stroke $[18,36]$. The extent to which our findings are generalizable to other countries with larger socio-economic differences and other working conditions than in Sweden remains to be seen. It should be noted that our findings regarding the general employed population were in line with those of previous reports from the UK [27], Belgium [28] and Australia [29], indicating high mortality in manufacturing workers. Moreover, Sweden's overall diabetes prevalence is in line with that in Europe as a whole [7].

Our findings indicate that job title can be used to find the groups that would benefit most from targeted workplace interventions. Hopefully, this knowledge can inspire employers whose employees have high risk of type 2 diabetes and poor prognosis if affected by type 2 diabetes to implement healthy lifestyle interventions to improve the health of their workforce.

\section{Supplementary Information}

The online version contains supplementary material available at https://doi. org/10.1186/s12933-021-01320-8.

Additional file 1. Additional tables and figures.

\section{Acknowledgements}

Not applicable.

\section{Authors' contributions}

SC conducted the literature search, interpreted the findings, and wrote, reviewed, and edited the manuscript. TA and SC conceptualized and designed the study. MT managed the register linkages and TA analyzed the data. MF, MT and TA made substantial contributions to the data interpretation and revision of the manuscript and approved the final draft. SC is the guarantor of the work 
and, as such, had full access to all the data in the study and takes responsibility for the integrity of the data and the accuracy of the data analysis. All authors read and approved the final manuscript.

\section{Funding}

Open access funding provided by Karolinska Institute. The study was funded by the Swedish Research Council for Health, Working Life and Welfare, Grant number 2020-00477.

\section{Availability of data}

The data that support the findings of this study are available from Statistics Sweden and the Swedish National Board of Health and Welfare, but restrictions apply to the availability of these data. They were used under license for the current study and are not publicly available.

\section{Declarations}

\section{Ethics approval and consent to participate}

The study was approved by the ethical review board in Stockholm (2017/70631). This was a registry-based study based on the entire Swedish population, thus no individual consent was available.

\section{Consent for publication}

Not applicable.

\section{Competing interests}

The authors have no conflict of interest to report.

\section{Author details}

${ }^{1}$ Institute of Environmental Medicine, Karolinska Institutet, 17177 Stockholm Sweden. ${ }^{2}$ Centre for Occupational and Environmental Medicine, Stockholm County Council, Stockholm, Sweden.

Received: 2 April 2021 Accepted: 17 June 2021

Published online: 26 June 2021

\section{References}

1. Emerging Risk Factors Collaboration, Sarwar N, Gao P, Seshasai SR, et al. Diabetes mellitus, fasting blood glucose concentration, and risk of vascular disease: a collaborative meta-analysis of 102 prospective studies. Lancet. 2010;375:2215-22.

2. Nathanson D, Sabale U, Eriksson JW, et al. Healthcare cost development in a type 2 diabetes patient population on glucose-lowering drug treatment: a nationwide observational study 2006-2014. Pharmacoecon Open. 2018;2:393-402.

3. Breton MC, Guénette L, Amiche MA, Kayibanda JF, Grégoire JP, Moisan J. Burden of diabetes on the ability to work: a systematic review. Diabetes Care. 2013;36:740-9.

4. Ervasti J, Virtanen M, Pentti J, Lallukka T, Tinghög P, Kjeldgard L, Mittendorfer-Rutz E, Alexanderson K. Work disability before and after diabetes diagnosis: a nationwide population-based register study in Sweden. Am J Public Health. 2015;105:e22-9.

5. Gaede P, Vedel P, Larsen N, Jensen GV, Parving HH, Pedersen O. Multifactorial intervention and cardiovascular disease in patients with type 2 diabetes. N Engl J Med. 2003:348:383-93.

6. Andersson T, Ahlbom A, Carlsson S. Diabetes prevalence in Sweden at present and projections for year 2050. PLoS ONE. 2015;10:e0143084.

7. Cho NH, Shaw JE, Karuranga S, et al. IDF diabetes atlas: global estimates of diabetes prevalence for 2017 and projections for 2045. Diabetes Res Clin Pract. 2018;138:271-81.

8. Brown SA, García AA, Zuñiga JA, Lewis KA. Effectiveness of workplace diabetes prevention programs: a systematic review of the evidence. Patient Educ Couns. 2018;101:1036-50.

9. Rawshani A, Svensson AM, Zethelius B, Eliasson B, Rosengren A, Gudbjörnsdottir S. Association between socioeconomic status and mortality, cardiovascular disease, and cancer in patients with type 2 diabetes. JAMA Intern Med. 2016;176:1146-54.
10. Wu H, Lau ES, Kong AP, et al. Association between educational level and cardiovascular disease and all-cause mortality in patients with type 2 diabetes: a prospective study in the Joint Asia Diabetes Evaluation Program. Clin Epidemiol. 2018;10:1561-71.

11. Carlsson S, Andersson T, Talbäck M, Feychting M. Incidence and prevalence of type 2 diabetes by occupation: results from all Swedish employees. Diabetologia. 2020;63:95-103.

12. Agardh E, Allebeck P, Hallqvist J, Moradi T, Sidorchuk A. Type 2 diabetes incidence and socio-economic position: a systematic review and metaanalysis. Int J Epidemiol. 2011;40:804-18.

13. Nyberg ST, Fransson El, Heikkilä K, et al. Job strain and cardiovascular disease risk factors: meta-analysis of individual-participant data from 47,000 men and women. PLoS ONE. 2013;8:e67323.

14. Wang D, Ruan W, Chen Z, Peng Y, Li W. Shift work and risk of cardiovascular disease morbidity and mortality: a dose-response meta-analysis of cohort studies. Eur J Prev Cardiol. 2018;25(12):1293-302.

15. Kawakami N, Akachi K, Shimizu H, et al. Job strain, social support in the workplace, and haemoglobin A1c in Japanese men. Occup Environ Med. 2000;57(12):805-9.

16. Manodpitipong A, Saetung S, Nimitphong H, et al. Night-shift work is associated with poorer glycaemic control in patients with type 2 diabetes. J Sleep Res. 2017:26(6):764-72.

17. Ludvigsson JF, Svedberg P, Olén O, Bruze G, Neovius M. The longitudinal integrated database for health insurance and labour market studies (LISA) and its use in medical research. Eur J Epidemiol. 2019;34(4):423-37.

18. Ludvigsson JF, Andersson E, Ekbom A, et al. External review and validation of the Swedish national inpatient register. BMC Public Health. 2011;11:450.

19. Wettermark B, Hammar N, Fored CM, et al. The new Swedish Prescribed Drug Register-opportunities for pharmacoepidemiological research and experience from the first six months. Pharmacoepidemiol Drug Saf. 2007; $1: 726-35$

20. Eliasson B, Gudbjornsdottir S. Diabetes care-improvement through measurement. Diabetes Res Clin Pract. 2014;106(Suppl 2):S291-4.

21. Statistics Sweden. Swedish Standard Classification of Occupations 1996. Official statistics of Sweden. 2001. https://www.scb.se/contentassets/ 50bf86d2c66149d696f515a9481 bc9e2/ov9999_1998a01_br_x70op9803. pdf. Accessed 24 July 2020.

22. International Labour Organization ISCO_International Standard Classification of Occupations. https://www.lo.org/public/english/bureau/stat/ isco/isco88/major.htm. Accessed 24 July 2020.

23. Perk J, De Backer G, Gohlke H, et al. European Guidelines on cardiovascular disease prevention in clinical practice (version 2012): the Fifth Joint Task Force of the European Society of Cardiology and Other Societies on Cardiovascular Disease Prevention in Clinical Practice (constituted by representatives of nine societies and by invited experts). Eur Heart J. 2012;33:1635-701.

24. Inzucchi SE, Bergenstal RM, Buse JB, et al. Management of hyperglycemia in type 2 diabetes, 2015: a patient-centered approach: update to a position statement of the American Diabetes Association and the European Association for the Study of Diabetes. Diabetes Care. 2015;38:140-9.

25. Statistics Sweden. Socio-economic classification system. 1984. https:// www.scb.se/contentassets/22544e89c6f34ce7ac2e6fefbda407ef/engli sh_ov9999_1982a01_br_x11 op8204-3.pdf. Accessed 14 May 2021.

26. Huang HL, Kung CY, Pan CC, et al. Comparing the mortality risks of nursing professionals with diabetes and general patients with diabetes: a nationwide matched cohort study. BMC Public Health. 2016;16:1054.

27. Katikireddi SV, Leyland AH, McKee M, Ralston K, Stuckler D. Patterns of mortality by occupation in the UK, 1991-2011: a comparative analysis of linked census and mortality records. Lancet Public Health. 2017;2:e501-12.

28. Vandersmissen GJM, Schouteden M, Verbeek C, Bulterys S, Godderis L. Prevalence of high cardiovascular risk by economic sector. Int Arch Occup Environ Health. 2020;93:133-42.

29. Kelsall HL, Fernando PHS, Gwini SM, Sim MR. Cardiovascular disease and type 2 diabetes risk across occupational groups and industry in a statewide study of an Australian working population. J Occup Environ Med. 2018:60:286-94.

30. Rawshani A, Rawshani A, Franzén S, et al. Risk factors, mortality, and cardiovascular outcomes in patients with type 2 diabetes. N Engl J Med. 2018;379:633-44. 
31. Dieleman $J$, Baral $R$, Birger $M$, et al. US spending on personal health care and public health, 1996-2013. JAMA. 2016;316:2627-46.

32. Andersson E, Persson S, Hallén N, et al. Costs of diabetes complications: hospital-based care and absence from work for 392,200 people with type 2 diabetes and matched control participants in Sweden. Diabetologia. 2020;63:2582-94

33. Hafez D, Fedewa A, Moran M, O'Brien M, Ackermann R, Kullgren JT. Workplace interventions to prevent type 2 diabetes mellitus: a narrative review. Curr Diab Rep. 2017:17:9.

34. Favaloro LE, Ratto RD, Musso C. Heart failure and diabetes: perspective of a dangerous association. Curr Hypertens Rev. 2021. https://doi.org/10. 2174/1573402117666210406111927 (Epub ahead of print).
35. Papazoglou AS, Kartas A, Samaras A, et al. Prognostic significance of diabetes mellitus in patients with atrial fibrillation. Cardiovasc Diabetol. 2021;20(1):40.

36. Eriksson A, Stenlund H, Ahlm K, Boman K, Bygren LO, Johansson LA, Olofsson BO, Wall S, Weinehall L. Accuracy of death certificates of cardiovascular disease in a community intervention in Sweden. Scand J Public Health. 2013;41:883-9.

\section{Publisher's Note}

Springer Nature remains neutral with regard to jurisdictional claims in published maps and institutional affiliations.
Ready to submit your research? Choose BMC and benefit from:

- fast, convenient online submission

- thorough peer review by experienced researchers in your field

- rapid publication on acceptance

- support for research data, including large and complex data types

- gold Open Access which fosters wider collaboration and increased citations

- maximum visibility for your research: over 100M website views per year

At BMC, research is always in progress.

Learn more biomedcentral.com/submissions 